\title{
Influence of Education Level on Mental Health and Medical Coping Modes: A Correlation Analysis in the Elderlies
}

\author{
Saisai Cui ${ }^{1}$, Rui Wang ${ }^{2}$, Leping Lu ${ }^{1}$, He Wang ${ }^{1}$, Yan Zhang ${ }^{1}$, \\ ${ }^{1}$ Health Management Center of the General Hospital of Northern Theater Command, Shenyang, China \\ ${ }^{2}$ Vcanbio Cell \& Gene Engineering CORP., LTD, Tianjin, China
}

Email address:

645876867@qq.com (Yan Zhang)

${ }^{*}$ Corresponding author

\section{To cite this article:}

Saisai Cui, Rui Wang, Leping Lu, He Wang, Yan Zhang. Influence of Education Level on Mental Health and Medical Coping Modes: A Correlation Analysis in the Elderlies. American Journal of Nursing Science. Vol. 8, No. 6, 2019, pp. 324-328.

doi: 10.11648/j.ajns.20190806.16

Received: September 27, 2019; Accepted: October 26, 2019; Published: November 8, 2019

\begin{abstract}
Objective: To investigate the influence of education level on mental condition and medical coping modes in the elderlies, which may provide some evidence for mental care in health management. Methods: Clinical Symptom Checklist 90 (SCL-90) and Medical Coping Modes Questionnaire (MCMQ) were applied to evaluate mental condition of 160 elderlies who were randomly chosen from the outpatients of a hospital in Shenyang. The patients were divided into 2 groups by education levels, highly educated group $(n=71)$ and non-highly educated group $(n=89)$. Scores of the two questionnaires were compared between the 2 groups, and correlation analysis was conducted between symptoms and medical coping modes within either group. Results: Compared with the non-highly educated group, the highly educated group has lower scores on all factors of SCL-90 and higher scores on all factors of MCMQ $(P<0.05)$. It was showed by the correlation analysis that "confrontation" was positively related to "psychoticism" in non-highly educated group $(P<0.05)$ but negatively related to "phobic anxiety" in highly educated group $(P<0.05)$, and "avoidance" was related to no factors of SCL-90 $(P>0.05)$, and "acceptance/resignation" was positively related to all the 9 factors of SCL-90 $(P<0.05)$ in non-highly educated group while positively related to 6 factors of SCL-90 $(P<0.05)$ except for "hostility", "phobic anxiety" and "psychoticism" $(P>0.05)$ in highly educated group. Conclusion: Highly education provides elderly people with more positive medical coping modes as well as better mental conditions.
\end{abstract}

Keywords: Education, Mental Health, Medical Coping Modes, Correlation Analysis, Health Management

\section{Introduction}

Education, in short, is to impart people with scientific knowledge and arguments to live their lives according to natural laws and principles. Education is an endlessly circulating process of raising questions, solving problems, and then making progressions. It is also a process of getting knowledge and information accepted and internalized into intelligence to support our lives [1].

Positive psychology aims to study the developing potential and the virtue of human [2-5]. The system of human life is open and self-determined [6,7]. People have inner conflict and the ability of self-remolding. Positive value contributes to the survival and development of human society, as well as the realization of the value of life [8]. So, it is highly important to maintain the mental health and positive values of social people $[9,10]$. This study took the elderly outpatients as the subjects who had much more life experience than the youth, the aim of which was to investigate the influence of education levels on their mental condition and medical coping modes, which might provide evidence for the management of mental health in elderlies.

\section{Objects and Methods}

\subsection{Object}

A simple random sampling method was used to choose 160 elderly patients with the age $\geq 60$ years old from the 
outpatient of a hospital in Shenyang from January 1, 2004, to June 30, 2006, including 107 males and 53 females, aged from 60 to 87 years old, with an average age of $73.26 \pm 6.20$ years old. The subjects were divided into two groups by their education levels: the highly educated group $(n=71)$ and the non-highly educated group $(n=89)$. There was no statistically significant difference in age and gender between the two groups $\left(\mathrm{t}=0.779, \mathrm{P}=0.438 ; \chi^{2}=0.725, \mathrm{P}=0.405\right)$.

\subsection{Tools}

1) Clinical Symptom Checklist 90 (SCL-90) [11, 12] was applied to the survey, which contained 90 items, including somatization, obsession-compulsion, interpersonal sensitivity, depression, anxiety, hostility, phobic anxiety, paranoia, and psychoticism, with a total of 9 factors. Positive detection criteria are: factor $\geq 2$ is moderate pain, $\geq 3$ is severe pain.

2) Medical Coping Questionnaire (MCMQ) [13-15], consisting of 20 items, was composed of three dimensions: confrontation, avoidance, and acceptance/resignation.

3) Questionnaire survey and data collection: Psychologists used unified questionnaires to conduct the surveys, which were filled by face-to-face method. Data input and error correction were carried out by two different collectors successively.

\subsection{Statistical Methods}

SPSS19.0 was used for statistical analysis, and t-test was conducted for comparison of data between groups, and Pearson correlation analysis was used. The level of statistical significance was $\alpha=0.05$.

\section{Results}

1) Comparison of psychosomatic health status (SCL-90) scores with domestic norm [16]: One hundred and fifty-six of the 160 cases had effective SCL-90 evaluations. Factors which scored no less than 2 of SCL-90 were: obsession and compulsion $(\mathrm{n}=46$, $29.49 \%)$, somatization $(\mathrm{n}=28,17.95 \%)$, depression $(\mathrm{n}=25,16.03 \%)$, anxiety $(\mathrm{n}=24,15.38 \%)$, interpersonal sensitivity $(n=21,13.46 \%)$, hostility $(n=21,13.46 \%)$, paranoia $(n=15,9.62 \%)$, phobic anxiety $(n=14,8.97 \%)$ and psychoticism $(\mathrm{n}=13,8.33 \%)$. Factors scoring no less than 3 were obsession and compulsion $(\mathrm{n}=8$, $5.13 \%)$, anxiety $(n=6,3.85 \%)$, depression $(n=6,3.85 \%)$, paranoia $(n=4,2.56 \%)$, somatization $(n=3,1.92 \%)$, interpersonal sensitivity $(\mathrm{n}=3,1.92 \%)$, hostility $(\mathrm{n}=3$, $1.92 \%)$ and phobic anxiety $(n=3,1.92 \%)$. It was showed by the statistical analysis that the scores of somatization, obsession and compulsion, and phobic anxiety of the elderly attending the hospital were all higher than those of the domestic norm of adults in China, while interpersonal sensitivity and hostility factors were lower than the norm $(\mathrm{P}<0.05)$, as shown in table 1 .

Table 1. Comparison of SCL-90 scores between the elderly patients and the domestic norm (mean $\pm S D$ ).

\begin{tabular}{llll}
\hline Factor & Elderly patients $(\mathbf{n = 1 5 6})$ & Domestic norm $(\mathbf{n = 1 3 8 8})$ & t \\
\hline Somatization & $1.643 \pm 0.546$ & $1.37 \pm 0.48$ & 6.239 \\
Obsession and compulsion & $1.755 \pm 0.560$ & $1.62 \pm 0.58$ & 2.814 \\
Interpersonal sensitivity & $1.494 \pm 0.573$ & $1.65 \pm 0.51$ & -3.393 \\
Depression & $1.529 \pm 0.607$ & $1.50 \pm 0.59$ & 0.588 \\
Anxiety & $1.452 \pm 0.533$ & $1.39 \pm 0.43$ & 1.448 \\
Hostility & $1.381 \pm 0.510$ & $1.48 \pm 0.56$ & -2.429 \\
Phobic anxiety & $1.325 \pm 0.446$ & $1.23 \pm 0.41$ & 0.006 \\
Paranoid & $1.362 \pm 0.540$ & $1.43 \pm 0.57$ & 0.557 \\
Psychoticism & $1.276 \pm 0.406$ & $1.29 \pm 0.42$ & 0.150 \\
\hline
\end{tabular}

2) Comparison of the scores of SCL-90 between the highly educated and the non-highly educated: The scores of SCL-90 of the non-highly educated group $(n=86)$ are all higher than those of the highly educated group $(n=70)(P<0.05)$, as shown in table 2 .

Table 2. Comparison of SCL-90 scores between the highly educated group and the non-highly educated group (mean \pm SD).

\begin{tabular}{llll}
\hline Factor & Highly educated group $(\mathbf{n}=\mathbf{7 0})$ & Non-highly educated group $(\mathbf{n}=\mathbf{8 6})$ & t \\
\hline Somatization & $1.545 \pm 0.474$ & $1.722 \pm 0.589$ & -2.029 \\
Obsession and compulsion & $1.650 \pm 0.606$ & $1.841 \pm 0.584$ & -1.994 \\
Interpersonal sensitivity & $1.394 \pm 0.512$ & $1.576 \pm 0.609$ & -2.002 \\
Depression & $1.418 \pm 0.502$ & $1.619 \pm 0.671$ & -2.143 \\
Anxiety & $1.349 \pm 0.487$ & $1.536 \pm 0.557$ & -2.048 \\
Hostility & $1.288 \pm 0.369$ & $1.457 \pm 0.592$ & -0.047 \\
Phobic anxiety & $1.240 \pm 0.331$ & $1.394 \pm 0.514$ & -2.180 \\
Paranoid & $1.270 \pm 0.304$ & $1.436 \pm 0.667$ & -2.255 \\
Psychoticism & $1.199 \pm 0.307$ & $1.338 \pm 0.464$ & $0.031^{*}$ \\
\hline
\end{tabular}

3) Comparison of MCMQ score with domestic norm [16]: One hundred and fifty-one subjects were evaluated effectively by MCMQS, including 67 in the highly educated group and 84 in the non-highly educated group. The comparison analysis found that the scores of the factor "confrontation" and "acceptance/resignation" were lower than the domestic norm, 
while the score of factor "avoidance" was higher than the norm $(\mathrm{P}<0.05)$, as shown in table 3.

Table 3. Comparison of $M C M Q$ scores between the elderly patients and the domestic norm (mean $\pm S D$ ).

\begin{tabular}{lllll}
\hline Factor & Elderly patients $(\mathbf{n}=\mathbf{1 5 1})$ & Domestic norm $(\mathbf{n}=\mathbf{6 5 0})$ & $\mathbf{t}$ & $\mathbf{P}$ \\
\hline Confrontation & $17.460 \pm 5.157$ & $19.48 \pm 3.81$ & -4.805 & $<0.001$ \\
Avoidance & $15.360 \pm 4.505$ & $14.44 \pm 2.97$ & 2.503 & 0.013 \\
Acceptance/resignation & $7.970 \pm 3.462$ & $8.81 \pm 3.17$ & -2.969 & 0.003 \\
\hline
\end{tabular}

4) Comparison of the scores of MCMQ: The 3 factors of the highly educated group are all higher than those of the non-highly educated group $(\mathrm{P}<0.05)$, as shown in table 4 .

Table 4. Comparison of MCMQ scores between the highly educated group and the non-highly educated group (mean $\pm S D$ ).

\begin{tabular}{lllll}
\hline Factor & Highly educated group $(\mathbf{n}=\mathbf{6 7})$ & Non-highly educated group $(\mathbf{n}=\mathbf{8 4})$ & $\mathbf{\text { }}$ & $\mathbf{P}$ \\
\hline Confrontation & $19.010 \pm 4.882$ & $16.230 \pm 5.062$ & 3.417 & 0.001 \\
Avoidance & $16.240 \pm 3.955$ & $14.650 \pm 4.808$ & 2.173 & 0.031 \\
Acceptance/resignation & $8.670 \pm 3.661$ & $7.420 \pm 3.208$ & 2.243 & 0.026 \\
\hline
\end{tabular}

5) Correlation analysis between MCMQ and SCL-90: Sixty-six cases in the highly educated group and 81 cases in the non-highly educated group had effective scores both in MCMQS and SCL-90 questionnaires. Correlation analysis found positive correlations between the total score of MCMQs of the non-highly educated group and factor "interpersonal sensitivity" and "psychoticism" ( $\mathrm{P}<0.05)$, and between the total score of the highly educated group and factor "interpersonal sensitivity" and "depression" $(\mathrm{P}<0.05)$. Among the 3 factors of MCMQ, "confrontation" was positively correlated with "psychoticism" in non-highly educated group $(\mathrm{P}<0.05)$, while negatively correlated with "phobic anxiety" in the highly educated group ( $\mathrm{P}<$ $0.05)$. There was no relationship between scores of "avoidance" and all SCL-90 factors in either group (P > 0.05). The score of "acceptance/resignation" was found positively correlated with that of every factor of SCL-90 ( $\mathrm{P}<0.05)$ in non-highly educated group. And the same relationships were found between "acceptance/resignation" and the SCL-90 factors except for "hostility", "phobic anxiety" and "psychoticism" in highly educated ones $(\mathrm{P}>0.05)$. (See table 5 and table 6).

Table 5. Correlation Analysis between MCMQ and SCL-90 in the highly educated group ( $n=66)$.

\begin{tabular}{|c|c|c|c|c|c|c|c|c|c|}
\hline & Somatization & $\begin{array}{l}\text { Obsession } \\
\text { and } \\
\text { compulsion }\end{array}$ & $\begin{array}{l}\text { Interpersonal } \\
\text { sensitivity }\end{array}$ & Depression & Anxiety & Hostility & $\begin{array}{l}\text { Phobic } \\
\text { anxiety }\end{array}$ & Paranoid & Psychoticism \\
\hline Total & 0.062 & 0.148 & $0.286^{*}$ & $0.244^{*}$ & 0.093 & 0.069 & -0.086 & 0.176 & 0.143 \\
\hline Confrontation & -0.121 & -0.006 & 0.185 & 0.144 & -0.069 & -0.024 & $-0.250^{*}$ & 0.116 & 0.037 \\
\hline Avoidance & 0.038 & 0.076 & 0.176 & 0.039 & -0.029 & -0.037 & 0.001 & -0.007 & 0.148 \\
\hline Acceptance/resignation & $0.291 *$ & $0.329 *$ & $0.341 *$ & $0.430 *$ & $0.376^{*}$ & 0.195 & 0.099 & $0.331 *$ & 0.180 \\
\hline
\end{tabular}

Table 6. Correlation Analysis between MCMQ and SCL-90 in the non highly educated group ( $n=81)$.

\begin{tabular}{|c|c|c|c|c|c|c|c|c|c|}
\hline & Somatization & $\begin{array}{l}\text { Obsession } \\
\text { and } \\
\text { compulsion }\end{array}$ & $\begin{array}{l}\text { Interpersonal } \\
\text { sensitivity }\end{array}$ & Depression & Anxiety & Hostility & $\begin{array}{l}\text { phobic } \\
\text { anxiety }\end{array}$ & Paranoid & Psychoticism \\
\hline Total & 0.069 & 0.201 & $0.219^{*}$ & -0.021 & 0.099 & 0.089 & 0.135 & 0.167 & $0.290 *$ \\
\hline Confrontation & -0.073 & 0.140 & 0.156 & 0.109 & 0.037 & 0.106 & 0.089 & 0.139 & $0.284 *$ \\
\hline Avoidance & -0.021 & 0.056 & 0.089 & -0.081 & -0.030 & -0.081 & 0.025 & 0.038 & 0.155 \\
\hline Acceptance/resignation & $0.369 *$ & $0.351 *$ & $0.333^{*}$ & $0.224 *$ & $0.310 *$ & $0.245^{*}$ & $0.261 *$ & $0.271 *$ & $0.267 *$ \\
\hline
\end{tabular}

\section{Discussion}

Compared with the norm, scores of all SCL-90 factors were found higher in elderlies who had health problems, while those of MCMQ factors such as "confrontation" and "acceptance/resignation" were lower. So, it was deduced that the mental health status of elderly patients was not as good as that of the healthy adults, and they tended to treat their health problems with negative modes such as "avoidance".

Comparison analysis showed difference in scores of SCL-90 and medical coping modes between the highly educated and the non-highly educated elderlies. The highly educated presented lower scores of SCL-90 and higher scores of MCMQ factors than the non-highly educated, which represented positive coping modes in the highly educated when confrontation illness.

Correlation analysis of MCMQ and SCL-90 in highly education and non-highly educated groups of the elderly found that the overall score of medical coping style in the highly educated group was positively correlated with "interpersonal sensitivity" and "depression", while that in the non-highly educated group was positively correlated with "interpersonal sensitivity" and "psychoticism". 
To the mode "confrontation", the symptom "psychoticism" showed positively correlation with it in the non-highly educated, but "phobic anxiety" showed negatively correlation in the highly educated. So, it was indicated that compared with non-highly educated elderlies, the highly educated had better awareness when confrontation a health problem, and they could cope with it more rationally rather than feeling terrified. Compared with the highly educated group, the non-highly educated group is more likely to be associated with "hostility", "phobic anxiety" and "psychoticism" when the medical coping methods is "acceptance/resignation". This means the non-highly educated are more likely to have fear and hostile emotions, and show psychotic symptoms and behaviors when they are forced to yield to diseases.

These differences between the two groups suggest that the education level of the elderlies affects the results of medical coping styles. More highly educated, more rational modes adopted. According to the data analysis of the sixth national population census in 2010, the proportion of the aged over 60 receiving highly education in China is only $3.26 \%$, which is far lower than the developed countries in Europe and America [17]. In China, it is highly suggested to provide the opportunity for the elderlies to be further educated by setting up the third-age universities $[18,19]$, encourage them to learn in groups and help each other, and promoting the use of web to study online [20], so that they can improve their mental health and medical coping modes. To provide quality assurance for highly education, some developed countries, such as the United States, the United Kingdom, New Zealand, Japan and so on, even established effective external assurance systems [21].

This study assured the positive influence of highly education on mental health and medical coping modes of the elderlies. Therefore, in the mental health management, more attention should be paid to the less educated, who should be special cared for further education, especially the popular health education. They may learn to understand diseases correctly, face and cope with their health problem rationally and objectively, and be treated effectively by cooperating with their doctors.

\section{Fund Project}

Subject of national science and technology support plan (2015BAH09F03).

\section{References}

[1] Huang Ping, Li Taiping. The definition of educational process and the interpretation of its generative characteristics [J]. Education research, 2013, 7, 18-27.

[2] KLOOS N, DROSSAERT C H C, BOHLMEIJER E T, et al. Online positive psychology intervention for nursing home staff: A cluster-randomized controlled feasibility trial of effectiveness and acceptability [J]. International Journal of Nursing Studies, 2019, 98, 48-56.
[3] RAYMOND I J, RAYMOND C M. Positive psychology perspectives on social values and their application to intentionally delivered sustainability interventions [J]. Sustainability Science, 2019, 14 (5), 1381-1393.

[4] SUN J, TANG X L. Research on Statistics and Analysis of Mental Health Status of Chinese College Students Based on Positive Psychology and T-test [J]. Basic Clin Pharmacol Toxicol, 2019, 124, 86-87.

[5] Zhang Hao. On the characteristics of positive psychology and its application in teaching [J]. Intelligence journal, 2014, 1 (30), 142.

[6] TAO K, LIU W X, XIONG S Y, et al. Associations between Self-Determined Motivation, Accelerometer-Determined Physical Activity, and Quality of Life in Chinese College Students [J]. Int J Environ Res Public Health, 2019, 16 (16), $1-15$.

[7] BOICHE J, SARRAZIN P, CHANAL J. A Longitudinal Study of Perceived Conflict and Instrumental Relationships Between Life Contexts Among Adolescents: The Role of Self-Determined Motivation [J]. J Appl Sport Psychol, 2015, 27 (4), 430-448.

[8] Zhang Rong, Cui Jiucai, Zhu Waner. Research progress in theory and application of positive psychology [J]. International journal of psychiatry, 2009, 3, 168-170.

[9] SMITH B A, GEORGIOPOULOS A M, QUITTNER A L. Maintaining mental health and function for the long run in cystic fibrosis [J]. Pediatr Pulmonol, 2016, 51, 71-78.

[10] ASHBY S, GRAY M, RYAN S, et al. Maintaining occupation-based practice in Australian mental health practice: A critical stance [J]. Br J Occup Ther, 2015, 78 (7), 431-439.

[11] WEI Y D, LI H Y, WANG H L, et al. Psychological Status of Volunteers in a Phase I Clinical Trial Assessed by Symptom Checklist 90 (SCL-90) and Eysenck Personality Questionnaire (EPQ) [J]. Med Sci Monitor, 2018, 24, 4968-7493.

[12] BECH P, BILLE J, MOLLER S B, et al. Psychometric validation of the Hopkins Symptom Checklist (SCL-90) subscales for depression, anxiety, and interpersonal sensitivity [J]. J Affect Disord, 2014, 160, 98-103.

[13] CHEN F X, CHEN X S, GUO J C, et al. Serotonin transporter-linked polymorphic region genotypes in relation to stress conditions among patients with papillary thyroid carcinoma [J]. Int J Clin Exp Pathol, 2019, 12 (3), 968-977.

[14] MA F Q, CAO H Y, SONG L J, et al. Effects of comprehensive care on mood and quality of life in infertile patients [J]. Int J Clin Exp Med, 2018, 11 (4), 4072-4079.

[15] SHEN X Y, ZHU X M, WU Y N, et al. Effects of a psychological intervention programme on mental stress, coping style and immune function in percutaneous coronary intervention patients [J]. PLoS One, 2018, 13 (1), 1-13.

[16] Wang Xiangdong, Wang Xilin, Ma Hong. Mental health rating scale manual [M]. Chinese Mental Health Journal, 1999.

[17] Zhang Hangkong. The present situation and changes of the education level of the elderly population in China [J]. Chinese journal of gerontology, 2016, 36 (5), 1215-1216. 
[18] SWINDELL R, VASSELLA K, MORGAN L, et al. University of the Third Age in Australia and New Zealand: Capitalising on the cognitive resources of older volunteers [J]. Australas Ageing, 2011, 30 (4), 196-201.

[19] ZIELINSKA-WIECZKOWSKA H. Correlations between satisfaction with life and selected personal resources among students of Universities of the Third Age [J]. Clin Interv Aging, 2017, 12, 1391-1399.
[20] ANDREWS J A, BROWN L J E, HAWLEY M S, et al. Older Adults' Perspectives on Using Digital Technology to Maintain Good Mental Health: Interactive Group Study [J]. J Med Internet Res, 2019, 21 (2), 1-11.

[21] Brennan J., Shah T. Managing quality in higher education: an international perspective on institutional assessment and change [J]. Quality Assurance in Education, 2000, 7 (2), 209-241. 